TÓPICOS. Revista de Filosofía de Santa Fe (Rep. Argentina) No 27-28, 2014, pp. 87-92

\title{
Reseña: Lozano-Vásquez, Andrea (comp.) Platón y la irracionalidad, Bogotá, Ediciones Uniandes, 2012
}

María Luz Omar

La compilación realizada por Andrea Lozano-Vásquez bajo el título Platón y la irracionalidad es resultado del III Congreso Colombiano de Filosofía llevado a cabo en Cali a finales de 2010. Los autores que integran esta compilación son profesores e investigadores con una sólida trayectoria en el área de la filosofía antigua que, como espero hacer patente en esta reseña, nos demuestran una vez más la vitalidad y complejidad de la filosofía platónica. Los artículos reunidos aquí enfocan, de diferentes maneras, los esfuerzos que Platón ha dedicado en distintos momentos de su vasto trayecto intelectual a estudiar lo irracional como un aspecto constitutivo de la humanidad que es preciso armonizar, en la medida en que ello sea posible, con los elementos racionales que también componen la vida humana. Los escritos se abocan especialmente a problemas de psicología, ética y educación, en ocasiones articulados con consideraciones sobre la metafísica y la dialéctica platónicas. Sin duda, el orden de los textos elegido busca seguir una organización atenta a la cronología de las obras platónicas, logrando abarcar muchos de sus diálogos fundamentales: Menón, Gorgias, Banquete, República, Filebo y Leyes.

En el artículo que inaugura esta compilación "Hacer del caso más débil el más fuerte: El Gorgias y la retórica socrática", Catalina González (UA) se anima a leer a contrapelo el Gorgias de Platón, al poner en cuestión la distinción que se suele plantear entre la dialéctica socrática y la retórica gorgiana. Su hipótesis, inspirada en Cicerón (De Oratore, I-47: 1), es que Sócrates utilizaría, en ocasiones, un modo de argumentación que involucra recursos de la retórica. Para demostrarla, González analiza el pasaje 461a-81b,

\footnotetext{
* Estudiante de la Licenciatura en Filosofía en la Facultad de Humanidades y Ciencias (UNL). Su investigación gira en torno a aspectos lingüísticos, gnoseológicos y éticos de los escritos del sofista Gorgias. Actualmente es becaria en el Programa de Becas de Iniciación a la Investigación del Consejo Interuniversitario Nacional. Dirección electrónica: luz.omar@gmail.com
} 
donde Sócrates emplea el procedimiento de hacer del argumento más débil el más fuerte y consigue refutar a Polo, su interlocutor, al conducirlo a aceptar que cometer injusticia es peor que recibirla, tesis que previamente se negaba a asumir. Según González, Sócrates no vencería precisamente por su habilidad dialéctica, sino por saber utilizar en beneficio de su argumentación la negativa de Polo a contradecir posiciones que provienen del sentido común. Lo relevante para la autora es que el diálogo no concluye en un rechazo de la utilización de la retórica -que se sirve, en ocasiones, de recursos espurios-, siempre y cuando ella se oriente a la búsqueda de la verdad y persuada sobre la conveniencia de llevar una vida moralmente buena.

El artículo siguiente "Inspiración divina en el Menón de Platón", que pertenece a Sergio Ariza (UA), analiza la paradójica respuesta final de este diálogo a la pregunta por el significado de la virtud. Luego de una esclarecedora presentación del estado de la cuestión en torno al tema, Ariza se propone argumentar que la noción final de virtud, propuesta en el Menón, como creencia adquirida por inspiración divina es incompatible con los resultados previamente alcanzados en el diálogo, que configuran una noción de virtud de naturaleza psíquica o disposicional. Su posición es que dicha concepción es irónica, pero también seria. Que la concepción es irónica lo demuestra argumentando que tanto la noción de virtud, como la de creencia y la de inspiración son opuestas a las que previamente ha defendido Sócrates en el diálogo. En cuanto a su seriedad, el autor señala que constituiría un modelo explicativo plausible para aquellos casos en que hombres grandiosos conducen correctamente sus ciudades; aunque no se trate más que de una imagen de la verdadera. Así, Ariza consigue dar una resolución plausible, con un sólido apoyo en el texto fuente, a los interrogantes que ha generado el final del Menón.

En "El residuo de lo irracional: reflexiones a propósito de algunos diálogos platónicos", se destaca el intento de María Angélica Fierro (UBA) de hallar una compatibilidad entre algunas posiciones antinómicas identificadas en los diálogos platónicos tempranos y de madurez. Con esta finalidad, Fierro pretende mostrar que el intelectualismo moral defendido en los diálogos tempranos y la tesis sobre la simplicidad del alma del Fedón deben ser entendidos como un ideal a alcanzar, en tanto que la visión tripartita del alma de República describiría adecuadamente la condición humana encarnada, que la vida filosófica contribuiría a racionalizar y simplificar. Esta concepción es, sin embargo, puesta en tensión con la idea, desarro- 
llada en el mito escatológico con que cierra República y en el mito del carro alado del Fedro, de que incluso en una existencia post mortem el alma no tendría la garantía de una eliminación completa de los restos de irracionalidad propios de la condición humana. Así, sin sobredimensionar ni negar ciertas tensiones intrínsecas al pensamiento de Platón, Fierro desarrolla una hipótesis de lectura factible que consigue organizar algunas tesis fundamentales de la ética, la teoría del alma y la propuesta educativa platónicas.

En el texto que sigue, Andrea Lozano-Vásquez (UA) se ocupa en detalle de un tema poco visitado en la literatura platónica, como es la educación de un componente irracional del alma a través de la música. "El adiestramiento del thymoeidés: el surgimiento de la conexión entre música y emoción en Platón" analiza de qué modo dicho componente irracional, denominado thymoeidés, que constituye la parte emotiva del alma, podría ser educado a través de la música, una actividad con características propias, diferente de la enseñanza conceptual. Habría, según la autora, dos abordajes dentro de República: aquel que considera a la música, según su contenido poético, como capaz de modelar virtuosamente la acción de los hombres, mediante un aprendizaje de creencias correctas acerca de lo que es virtuoso, y aquella que entiende la música, según su carácter melódico, como capaz de temperar las pasiones, comprendidas como movimientos del alma. Esta última perspectiva sería aquella a la que más se aproxima el pensamiento de Platón, hipótesis que el texto corrobora acudiendo a pasajes pertenecientes al corpus aristotélico. En el artículo se integra también un examen del tratamiento que da a este tema el filósofo estoico Posidonio, donde se pone en evidencia la influencia que recibe del vocabulario y pensamiento platónicos y se encuentra una propuesta que al parecer acepta más abiertamente la condición irracional tanto de la formación musical como de la parte del alma a la que se dirige. Mediante este estudio, se trataría de responder en qué medida y de qué modo entiende Platón que podría colaborar el aprendizaje de la mousiké en el desarrollo de una vida feliz. La cuestión no queda totalmente cerrada, al dejarnos el interrogante sobre la posibilidad de que, a la mirada platónica, aquellos hombres cuyo componente irracional resulta preeminente desarrollen una vida feliz a través de los recursos que provee la música.

En "Éros y racionalidad: algunas consideraciones sobre el Banquete", Jairo Iván Escobar (U. Antioquía), se propone argumentar que el motivo de Éros reconcilia ciertos momentos irracionales intrínsecos a la teoría del conocimiento platónica. En su desarrollo es relevante el análisis del papel 
que cumple éros en cada uno de los siete discursos del Banquete, pero cobran centralidad, especialmente, las disertaciones de Aristófanes y Sócrates. Ambos estarían de acuerdo al considerar el amor como una carencia, si bien el segundo, al explicar el progreso del conocimiento humano hacia lo divino, transformaría el amor en algo más espiritual. El autor enfatiza entonces que, a la mirada de Platón, la existencia humana oscilaría entre las carencias propias de su existencia y el anhelo de reducir dichas carencias al mínimo, con vistas a alcanzar la plenitud cognoscitiva.

Los siguientes dos artículos son recomendables como lecturas complementarias para quien desee abordar y conocer el trayecto que Platón realiza en Filebo con vistas a determinar cuáles serían los aspectos constitutivos de una vida feliz. Alfonso Correa (UNCol), en su artículo "Conocer y elegir el bien: Filebo 20b-22e" se ocupa específicamente de un pasaje relevante del diálogo, donde los interlocutores -Sócrates y Protarco- revisan sus respectivas propuestas, intelectualista y hedonista, respecto de lo que habría de calificarse como una vida feliz, y terminan concordando en que una tercera alternativa, denominada vida mixta, sería la más adecuada. El autor analiza en detalle los requisitos formales de autosuficiencia y elegibilidad para calificar una vida como buena, que resultan fundamentales para configurar el objeto ético, en tanto debe ser cognoscible y deseable. La imposibilidad de cumplir con estas condiciones impediría que el hedonismo y el intelectualismo sean candidatos a la vida buena. Mientras que el aspecto racional se mantendría por la necesidad de que el bien sea conocido, el rasgo motivacional emergería del reconocimiento del estado de carencia que supone para el hombre el conocimiento del bien. En este sentido, el conocimiento del bien no garantiza una vida buena, pero sí el deseo de efectuarla. Dicho deseo estaría motivado por el sentimiento de dolor que supone la carencia, cuya satisfacción solamente puede conducir a un estado de placer, el cual, sin embargo, no parece ser permanente. Correa enfatiza que la propuesta de una vida mixta como la forma de vida buena más adecuada es presentada como la más autosuficiente entre las esbozadas, pero no como efectivamente autosuficiente. Considera, sin embargo, que esta limitación permite romper con un modo dicotómico de formular preguntas éticas y otorgar complejidad a la configuración de una vida feliz.

En "Sobre las condiciones de la vida racional y afectiva humanas en el Filebo", el texto más extenso de esta compilación, Fabián Mié (UNL) 
aborda con exhaustividad lo que considera es el plan de este diálogo: construir una propuesta respecto de cómo debe estar compuesta y ser conducida una vida humana para que sea buena, integrando sus dos aspectos constitutivos básicos, la racionalidad y la afectividad. Mié reúne en sus análisis consideraciones de orden metodológico planteadas en el texto, y da cuenta de la razonabilidad y necesidad de un conjunto de precisiones ontológicas también desarrolladas. Lo que desde nuestro punto de vista resulta notable en este trabajo es el esclarecimiento del andamiaje conceptual que constituye la teoría del alma platónica, según la cual se interpreta el placer como un estado afectivo del alma y se propone integrar uno de sus géneros, llamado puro, a la vida buena. Este tipo de placer pertenece al género de lo limitado y se caracteriza por estar asociado a un tipo de necesidad diferente del dolor; afección que acompaña, en cambio, a los placeres mezclados, al ser estos últimos siempre relativos en cuanto a su intensidad y por poseer una relación con su contrario. Así, este artículo precisa de qué modo, en la propuesta del Filebo, la vida buena humana combina estados afectivos placenteros, comportamientos y conocimientos racionales, todos ellos necesariamente ordenados por la razón. Este último componente se presenta como el más relevante en cuanto es el encargado de dirigir la realización de la vida humana en orden al bien.

En el último artículo que compone este libro, titulado "Una insistencia de Platón: a propósito de la 'verdadera tragedia' (Leyes, 817a-d)", André Laks se propone analizar un pasaje problemático de Leyes que constituye una reformulación de la exclusión de la poesía propuesta en República y, a su vez, una reapropiación de la tragedia como característica de la forma de vida desarrollada en la nueva ciudad. Luego de detallar las diferencias que se dan, entre una obra y otra, en el concepto de tragedia para que sea posible su reapropiación, Laks precisa que ésta podría ser integrada a la ciudad de las Leyes como un elemento que serviría en la reglamentación de comportamientos ilícitos, en la medida en que representa secuencias virtuosas de crimen y castigo. En este sentido, la vida regida por la constitución de las Leyes se configuraría como una verdadera tragedia, en la medida en que las transgresiones invocan sus respectivos castigos, lo que conduce a una concepción optimista de la tragedia. Pero, también la noción de verdadera tragedia podría entenderse a partir de la idea de ley como imperativo, que adquiriría inevitablemente una forma violenta en su aplicación, algo que 
conduciría a una concepción pesimista de la tragedia. El autor enfatiza la plausibilidad de ambas nociones y señala que la tensión entre ellas se apoya en una dualidad fundamental que sería intrínseca a la naturaleza humana.

Como hemos intentado dejar en evidencia, los artículos que conforman esta valiosa compilación ofrecen perspectivas de la filosofía platónica con sus respectivos matices, algunos de ellos atendiendo a los modos en que Platón considera posible atemperar al máximo los componentes irracionales de la vida humana; otros, enfatizando la inevitable permanencia de un resto irracional como aspecto irreductible de los hombres. Los escritos poseen algo en común: abordan las múltiples formas de lo irracional preferentemente dentro de dos áreas de estudio, la ética y la teoría del alma. Tal rasgo común nos muestra que el problema de la irracionalidad emerge, en los diálogos platónicos, como un aspecto especialmente atinente a la vida de los hombres, al que no es posible dar la espalda dentro de un proyecto filosófico que intenta responder a la pregunta por el desarrollo de una vida humana buena y feliz.

Recibido: 3/2014; aceptado: 4/2014 